\title{
O ENSINO DA ESTATÍSTICA: competências a serem desenvolvidas
}

THE TEACHING STATISTICS: competencies to be developed

\author{
Dalcio Schmitz ${ }^{1}$ \\ Marcio Bennemann²
}

\begin{abstract}
Resumo
O ensino da estatística, no Ensino Fundamental, tem como objetivo levar o aluno a entender, vivenciar e utilizar a estatística presente nas atividades de seu dia a dia. O presente artigo trata-se de um estudo bibliográfico sobre questões do ensino da estatística segundo as habilidades que a disciplina se propõe a desenvolver, abordando a relevância e o desenvolvimento das três competências: literacia, raciocínio estatístico e pensamento estatístico. Como resultado, consideramos a identificação das bases teóricos necessárias para a formação de sujeitos capazes no trato da informação fundamentada em dados.
\end{abstract}

Palavras-chave: Educação Estatística. Literacia. Raciocínio Estatístico. Pensamento Estatístico.

\begin{abstract}
The teaching of statistics, in elementary school, aims to lead the student to understand, experience and use the statistics present in their daily activities. This article deals with a bibliographic study on issues of teaching statistics according to the skills that the discipline proposes to develop, addressing the relevance and development of the three competencies: literacy, statistical reasoning and statistical thinking. As a result, we consider the identification of the theoretical bases necessary for the formation of capable subjects in dealing with information based on data.

Keywords: Statistical Education. Literacy. Statistical Reasoning. Statistical Thinking.

\footnotetext{
${ }^{1}$ Mestre em Matemática, pela M Universidade Tecnológica Federal do Paraná. Docente da Universidade Paranaense Campus Francisco Beltrão. E-mail: dalcios@gmail.com

${ }^{2}$ Doutor em Ensino de Ciências e Matemática pela Universidade Cruzeiro do Sul. Docente da Universidade Tecnológica Federal do Paraná. E-mail: marciobennemann@yahoo.com.br
} 


\section{Introdução}

O presente trabalho tem por objetivo fornecer um estudo descritivo, teórico (e empírico) acerca do ensino da estatística em geral, assim como os aspectos que o envolvem em relação à educação e às tecnologias. Justifica-se pela grande importância que tem tal tema em diversas áreas, como por exemplo: Matemática, Ciência e Tecnologia; não apenas em âmbito acadêmico como também pragmático e científico.

Far-se-á um esforço para promover uma conceituação sólida, após o que se dará uma descrição de aspectos indispensáveis ao estudo das técnicas relacionadas ao ensino da estatística: como é aplicado e como se caracterizam os diferentes tipos de abordagens educativas, além dos desafios enfrentados relacionados ao aprendizado, relação e influência com outras áreas do conhecimento etc.

Devido à natureza da proposta que ora se apresenta, recorrer-se-á metodologicamente à revisão bibliográfica para a promoção de um estudo descritivo fundamentado em artigos científicos, obras completas e demais produções científico-acadêmicas que se mostrem úteis e pertinentes à pesquisa em tela.

Os dados serão avaliados através de interpretação, análises e comparações de visões contrastantes de autores acerca dos assuntos trabalhados, com foco, também, em suas variantes.

Serão discutidas as principais características do ensino da estatística e as formas mais eficazes de abordá-la dentro das salas de aula em seus aspectos interdisciplinares. 
Almeja-se com o presente trabalho ajudar a preencher lacunas teóricas no entendimento acerca das questões que norteiam o ensino da estatística e o ambiente de sala de aula, através do fornecimento de conclusões fáticas que, além de seu interesse geral e específico no âmbito da educação, podem servir de base para futuros trabalhos.

\section{O Ensino da Estatística}

No dia a dia, pessoas se deparam ou usam a estatística e, muitas vezes, nem a percebem ou sabem que a estão usando. A estatística vem para ajudar a planejar a obtenção de dados, a interpretar e a analisar os dados obtidos e a apresentar os resultados de maneira a facilitar a sua tomada de decisões, nas diferentes áreas do conhecimento humano.

O ensino da estatística não se resume apenas a números e a grãficos, é uma ferramenta que auxilia nas respostas aos questionamentos viabilizando uma descrição clara e objetiva de fenômenos da natureza. O estudo da estatística auxilia no desenvolvimento de habilidades, dentre elas podemos destacar a organização, o senso crítico e análise.

Damin (2015, p. 11) salienta que:

(...) trabalhar o tema Estatística é um desafio para o professor de Matemática, uma vez que cabe ao docente a tarefa de possibilitar as oportunidades de conhecimento junto aos limites e possibilidades da sala de aula.

Para tanto, faz-se necessário, segundo o autor, buscar aporte teórico e novas metodologias a fim de se desenvolver, adequadamente, o ensino da Estatística, bem como pode possibilitar uma melhor compreensão por parte dos alunos. 
Claro que, somente o estudo desse tema, não garante ao aluno desenvolver todas as habilidades necessárias, mas contribui significativamente no desenvolvimento de análises críticas e argumentação. Isso implica em dizer que não basta o aluno entender de cálculos ou porcentagem, de gráficos e tabelas, precisamos sim, que o aluno seja capaz de interpretar e analisar criticamente todo o contexto dos dados.

Para tanto, é fundamental que o aluno levante dados de situações de seu cotidiano, organize esses dados, calcule estatísticas e/ou parâmetros e, respaldado pelo professor, possa discutir os resultados, analisar a estratégia utilizada, verificar existência de erros e, efetuar análises dos resultados obtidos. Nesse contexto, o aluno passa a desenvolver sua criticidade e outras habilidades, na perspectiva do ensino da estatística.

Em seu trabalho sobre o ensino da estatística e da probabilidade na educação básica, Lopes (2008, p. 58) aponta que:

O estudo desses temas torna-se indispensável ao cidadão nos dias de hoje e em tempos futuros, delegando ao ensino da matemática o compromisso de não só ensinar o domínio dos números, mas também a organização de dados, leitura de gráficos e análises estatísticas.

Simonelli e Raimundo (2011, p. 08) recomendam que uma forma ideal de dar início ao ensino da estatística nas escolas é "aproveitar as experiências dos alunos e então utilizá-las como material de ensino".

Dessa forma, os autores acreditam que tal perspectiva pode ser conquistada por meio da utilização de brincadeiras, jogos, desenhos, literatura infantil, dentre outros meios. Portanto, fazendo uso de tais alter- 
nativas, o professor consegue dar noções de simbologia, de números, medidas, valores máximos e mínimos, média etc.

Possibilitar que as pessoas averiguem indices de custo de vida, performem sondagens, façam escolhas quanto a amostras e tomem decisões em diferentes situações do cotidiano, com sucesso, requer um sólido conhecimento estatístico.

Diante disso, cada vez mais observamos um aumento na presença e importância da estatística em diferentes áreas de formação acadêmica e no próprio Ensino Básico.

De acordo com Lopes,

A Educação Estatística apresenta atualmente, em suas linhas de pesquisas, investigações sobre currículos da escola básica e da universidade, formação inicial e conti-nuada de professores, erros e dificuldades dos estudantes e novas tecnologias. A Estatística é uma ciência que não se restringe a um conjunto de técnicas. Ela contribui com conhecimentos que permitem o lidar com a incerteza e a variabilidade dos dados, mesmo durante a coleta, possibilitando tomadas de decisão com maior argumento. (LOPES, 2003, p. 56).

Segundo os PCN de Matemática, "Com relação à estatística, a finalidade é fazer com que o aluno venha a construir procedimentos para coletar, organizar, comunicar e interpretar dados, utilizando tabelas, gráfi$\cos$ e representações que apareçam frequentemente no seu dia-a-dia" (BRASIL, 2001, p. 56).

Diante disso, há a preocupação de trabalhar o ensino de estatística de maneira a não colocar o professor como peça central desse ensino, mas usar convivências e conhecimentos prévios dos alunos, principal- 
mente relacionando ao seu cotidiano. Essa educação estatística envolvendo o dia a dia do aluno possibilita, muitas vezes, conhecer aspectos presentes na sociedade antes despercebidos.

Dessa maneira, Campos, Wodewotzki e Jacobini (2011, p. 12) destacam que:

Valorizando atitudes voltadas para a práxis social, os alunos se envolvem com a comunidade, transformando reflexões em ação (...) esse aspecto crítico da educação é indissociável da educação estatística e, mais que isso, nela encontra fundamento e espaço para seu desenvolvimento.

Isso tudo se revela como um desafio, visto que apesar da estatística ser trabalhada como uma parte da matemática no ensino básico, essas disciplinas podem ter caminhos pedagógicos diferentes. Batanero (2001, apud CAMPOS; WODEWOTZKI; JACOBINI, 2011) observa que é preciso experimentar e avaliar métodos de ensino adaptados à natureza específica da estatística, pois a ela nem sempre se podem transferir os princípios gerais do ensino da matemática.

Conforme Campos, Wodewotzki e Jacobini (2011), as estratégias pedagógicas utilizadas na educação estatística fundamentam-se na organização e desenvolvimento curricular onde o aluno é o centro, tornando-se protagonista de sua aprendizagem, se apropriando das competências necessárias.

Campos (2007, p. 174) considera como fundamentais três competências que devem ser desenvolvidas no estudo da Estatística e, sem elas, seria impossível aprender ou, até mesmo, compreender os conceitos básicos dessa disciplina, são elas: a literacia (letramento), o raciocínio e o pensamento estatístico. 
De acordo com Silva (2007, p. 78), considera que o "nível de letramento de um individuo depende de outras duas competências que sustentam o letramento estatístico", que são elas o raciocínio e o pensamento estatístico, e, de acordo com o autor, "quanto mais apurado o raciocínio e pensamento estatístico, maior o letramento estatístico".

\section{Literacia Estatística}

Uma das primeiras tentativas de definição do termo literacia foi feita por Wallman (1993), o qual combinava a capacidade de compreender e avaliar criticamente os resultados estatísticos que permeiam a vida diária com a capacidade de ponderar as contribuições que a estatística pode trazer para tomadas de decisões.

Garfield (1998, apud CAMPOS; WODEWOTZKI; JACOBINI, 2011) considera a literacia estatística como sendo o entendimento da línguagem estatística, ou seja, sua terminologia, símbolos e termos, a habilidade em interpretar gráficos e tabelas, em entender as informações estatísticas dadas nos jornais e outras mídias.

Para Sedlmeier (1999, citado por CAMPOS; WODEWOTZKI; JACOBINI, 2011), a literacia é a arte de extrair inferências racionais com base em uma abundância de números e informações providas pela mídia diariamente e se configura como uma capacidade indispensável para o exercício da cidadania, tanto quanto ler e escrever.

Ainda, de acordo com Gal (2002, p. 93), a literacia assimila não apenas os "conhecimentos factuais, certas destrezas formais e informais" como, também as "crenças, hábitos e atitudes assim como uma perspectiva crítica desses conhecimentos". 
Como descrito anteriormente, esse conceito, ao longo do tempo, foi lapidado por diversos pesquisadores. Um dos mais concisos ao distinguir a literacia estatística foi Gal (2002), ao mostrar dois componentes pertinentes. O componente cognitivo relativo à capacidade das pessoas para interpretar e avaliar criticamente a informação estatística, utilizando argumentos relacionados aos dados ou a fenômenos estocásticos encontrados em diversos contextos. E a componente afetiva referente à capacidade de discutir ou comunicar suas reações às informações estatísticas, tais como a compreensão do significado da informação, suas opiniões e entendimentos sobre o seu significado e a suas preocupações em relação à aceitabilidade dos dados contidos nas conclusões.

Ambas as competências não devem ser tratadas distintamente, e sim juntas, pois se baseiam em várias bases de conhecimento interrelacionados que auxiliam os alunos a compreenderem situações do seu cotidiano.

Nesse sentido, há uma preocupação em discutir e ter clareza sobre as características da construção da literacia estatística. Em meio a tantos tipos de exposição de elementos estatísticos na mídia em geral como informações estatísticas escritas, com números e símbolos ou por meio de gráficos e tabelas a preocupação com a capacidade das pessoas em agir eficazmente nas suas ações é muito grande.

Dessa forma, Gal (2002) propõe um modelo de literacia estatística composta por cinco elementos cognitivos: exercício de literacia; conhecimentos de estatística; conhecimentos matemáticos; conhecimento do contexto; questionamento crítico, e por dois elementos afetivos: crenças e atitudes; sentido crítico. 
O ensino da Estatística: competências a serem desenvolvidas

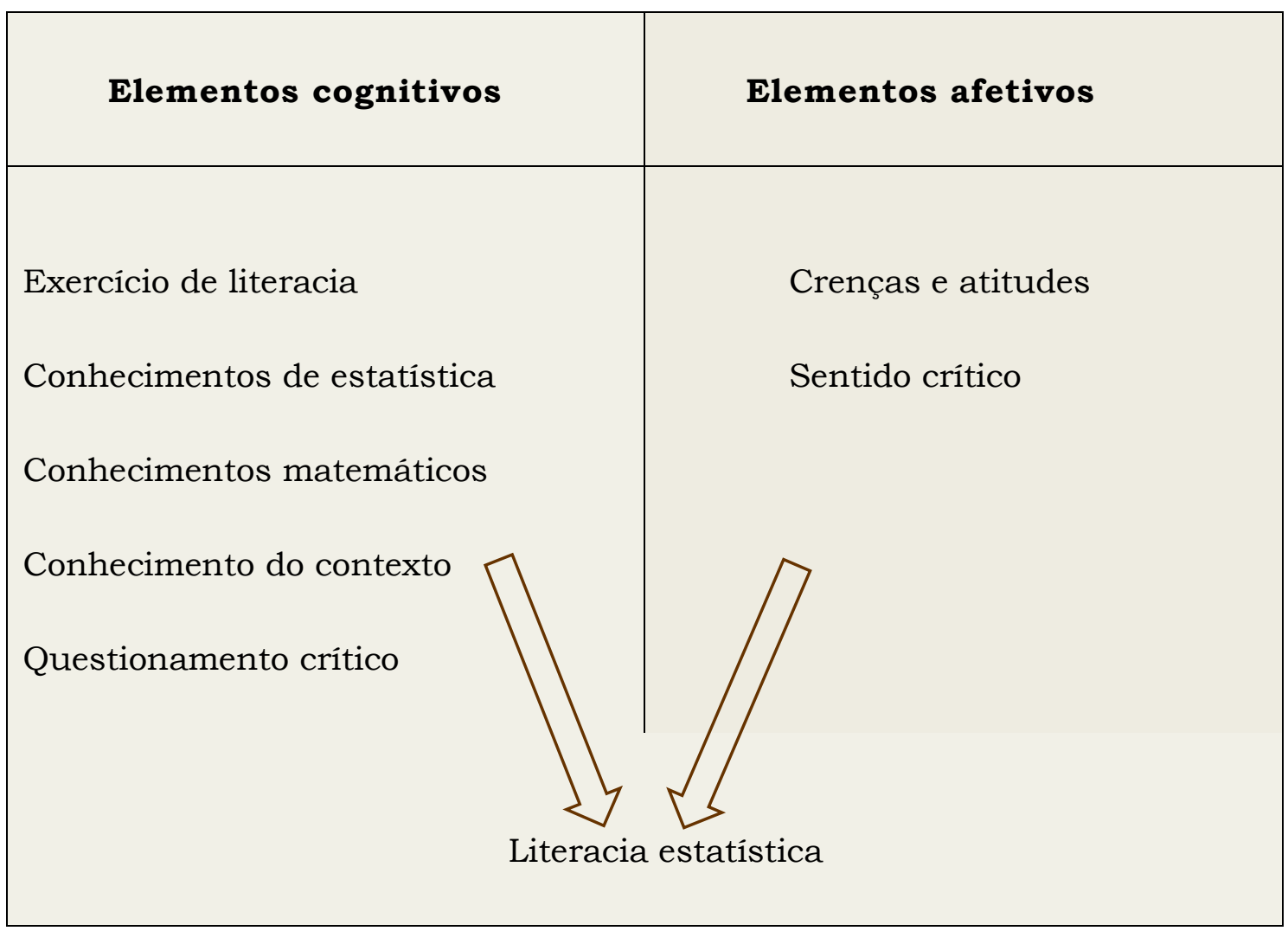

Tabela 1: Um modelo de literacia estatística (GAL, 2002, p. 51)

As informações estatísticas que são adquiridas pelas pessoas, precisam ser compreendidas e interpretadas, mas para isso não podemos exigir das pessoas apenas o conhecimento estatístico, precisamos envolver outras bases de conhecimento, como matemática, e também o contexto onde estão inseridas essas informações. Assim é importante garantir o processo do desenvolvimento da literacia estatística, não necessariamente separando os elementos citados por Gal, mas sim interligando os mesmos, pois ajudam conjuntamente as pessoas na compreensão, interpretação e tomada de decisões. 


\section{Habilidades de literacia}

Sobre a necessidade do desenvolvimento da literacia estatística précisamos discutir sobre outra competência básica e especifica de literacia. A compreensão de mensagens estatísticas requer o envolvimento de habilidades linguísticas que deverão ser usadas para extrair significados em textos que podem ser apresentados em partes curtas, mas também longas. Em outros casos existe a necessidade do individuo compreender um texto maior que associa a mensagem estatística ou em casos em que são apresentados gráficos com poucas palavras.

Assim, Gal (2002) analisa que, para lidar com mensagens matemáticas ou estatísticas, existem várias demandas sobre as competências de literacia dos indivíduos. Uma característica importante é o alcance, desde as operações cognitivas necessárias para localizar informações e as estratégias de leitura que combinam informações de uma questão com diferentes gráficos e tabelas.

Segundo a UNECE (2012), a literacia estatística é um termo usado para descrever a capacidade de um indivíduo ou de um grupo para entender e compreender as estatísticas. É um conceito que vem sendo muito discutido nos últimos anos. Muitos autores têm estudado e modelado o significado para literacia estatística.

Nesse sentido,

A literacia estatística refere-se ao estudo de argumentos que usam a estatística como referência, ou seja, à habilidade de argumentar usando corretamente a terminologia estatística (...) inclui também habilidades básicas e importantes que podem ser usadas no entendimento de informações estatísticas. Essas habilidades incluem as capacidades de organizar dados, construir e apresentar tabelas e trabalhar com 
O ensino da Estatística: competências a serem desenvolvidas

diferentes representações dos dados (...) também inclui um entendimento de conceitos, vocabulário e símbolos e, além disso, um entendimento de probabilidade como medida de incerteza. (CAMPOS; WODEWOTZKI; JACOBINI, 2011, p. 23).

Assim, desenvolver a literacia estatística significa:

Ressaltar o conhecimento sobre os dados; o entendimento de certos conceitos básicos de estatística e da sua terminologia; o conhecimento sobre o processo de coleta de dados; a habilidade de interpretação para descrever o que os resultados alcançados significam para o contexto do problema; a habilidade de comunicação básica para explicar os resultados a outras pessoas. (CAMPOS; WODEWOTZKI; JACOBINI, 2011, p. 117-118).

Para isso os educadores precisam instigar os estudantes à discussão, à valorização das suas ideias. Contudo, é necessário que os estudantes conheçam onde está inserido o problema e dominem conhecimentos estatísticos e matemáticos para terem um correto entendimento e a melhor interpretação da informação estatística.

\section{Raciocinio Estatístico}

A educação estatística tem uma dimensão diferente das áreas normalmente consideradas como ramos da Matemática, como, por exemplo, a Geometria, a Análise e a Álgebra, pelo seu envolvimento direto com o estudo de outras ciências como as ciências médicas e afins, ciências politicas e ciências sociais.

De acordo com Garfield (2002), raciocínio estatístico é a maneira que uma pessoa raciocina com ideias estatísticas e faz sentido com as 
informações estatísticas. Assim, o raciocínio estatístico ajuda a abranger conceitos de vários conteúdos estatísticos e a obter ideias de combinação dos mesmos. Conforme Campos, Wodewotzki e Jacobini (2011), raciocínio estatístico também significa entender um processo estatístico e ser capaz de explicá-lo, além de interpretar por completo os resultados de um problema baseado em dados reais.

Alguns autores como Garfield e Gal (1999, apud CAMPOS; WODEWOTZKI; JACOBINI, 2011) estabelecem alguns tipos especificos de raciocínio que são desejáveis que os estudantes desenvolvam em suas aprendizagens estatísticas: raciocínio sobre dados, raciocínio sobre representação dos dados, raciocínio sobre medidas estatísticas, raciocínio sobre incerteza, raciocínio sobre amostras e raciocínio sobre associações.

A grande discussão é em como estimular o desenvolvimento desses raciocínios e fazer com que o aluno seja capaz de saber o significado e a compreensão do conteúdo estatístico e o que ele pode mostrar, revelar sobre um conjunto de dados retirados do seu cotidiano.

Gregório (2012, p. 14 apud Wild e Pfannkuch, 1999, p. 73) apresenta, em seu texto, que uma base do raciocínio estatístico possui cinco tipos de pensamento, ele os discute:

1. Reconhecimento da necessidade dos dados, relacionado com o reconhecimento de que as experiências pessoais não são fiáveis e são insuficientes para fundamentar tomadas de decisão;

2. Transnumeração, que ocorre quando a interpretação de dados conduz a novos significados, indicando que a compreensão pode surgir ao alterar a representação de dados; 
3. Variação, quando está presente a percepção da influência da variabilidade dos dados, bem como a incerteza originada pela variação não explicada;

4. Um conjunto de modelos distintos: quando são utilizados modelos para representar a realidade, compreendendo que modelo e realidade são conceitos distintos (Todos os pensamentos usam modelos);

5. O conhecimento do contexto, conhecimento estatístico e sínteses: quando é o resultado (síntese) de implicações e conjeturas originadas pelo conhecimento estatístico num determinado contexto a partir dos dados disponiveis.

Seguindo esse entendimento,

Se os professores estiverem atentos aos tipos de raciocínio que precisam reforçar em seus estudantes, podem promover atividades para ajudar a desenvolvê-los. Da mesma forma, podem propiciar atividades nas quais possam avaliar o nivel de desenvolvimento do raciocínio dos estudantes, para melhor direcionar suas aulas e assim favorecer o aprendizado dos seus alunos. Acreditamos que isso não seja uma tarefa simples, mas o entendimento da hierarquização dos niveis de desenvolvimento do raciocínio estatístico, conforme apresentado por Garfield, nos dá uma ideia de que os erros dos alunos podem favorecer importantes informações sobre suas falhas de raciocínio. Observando isso, o professor pode procurar desenvolver estratégias que possibilitem o enfrentamento e a superação dessas falhas por conta do desenvolvimento correto do raciocínio. (CAMPOS; WODEWOTZKI; JACOBINI, 2011, p. 35).

O incentivo para desenvolver esses raciocínios é um grande desafio aos professores para que utilizem procedimentos e atividades que proporcionem e ajudem na ampliação e desenvolvimento do raciocínio estatístico. 
Dessa forma, Campos et al. (2011, p. 481) acredita que o raciocínio estatístico abrange a elaboração de interpretações em relação a dados, tabelas e gráficos, além de compreender ideias e teses de hipóteses.

Ainda, segundo o autor, "significa entender e ser capaz de explicar um processo estatístico, e ter a capacidade de interpretar, por completo, os resultados de um problema baseado em dados reais". (CAMPOS et al., 2011, p. 481).

Gregório (2012, p. 32 apud GARFIELD, 2002), em seu texto, afirma que o autor citado coloca o foco em alguns tipos - corretos - de raciocínio estatístico:

a) raciocínio sobre dados: reconhecer ou categorizar os dados e entender as formas de representações;

b) raciocínio sobre representação dos dados: compreender como os gráficos podem ser modificados para representar melhor um conjunto de dados;

c) raciocínio sobre medidas estatísticas: entender o que representa as medidas de tendência central e qual medida é a mais adequada em cada caso;

d) raciocinio sobre incerteza: usar adequadamente ideias de aleatoriedade e probabilidade para fazer julgamentos sobre eventos que envolvem incerteza;

e) raciocínio sobre amostras: entender a relação entre a amostra e a população, fazendo-se cético com inferências feitas a partir de pequenas amostras;

f) raciocínio sobre associação: entender como julgar e interpretar a relação entre duas variáveis, interpretar uma tabela de dupla entrada. Entender que uma forte correlação entre duas variáveis não significa que uma cause a outra. 
Simonelli e Raimundo (2011, p. 21) explicam que se faz possivel dizer que a estatística, assim como a disciplina matemática, "contribui para a atividade do pensamento". Dessa forma, os autores comentam ainda que a estatística "caracteriza-se pela aquisição das operações e das estruturas lógicas elementares de raciocínio, próprias do periodo em que a criança está".

\section{Pensamento Estatistico}

Para Chance (2002), numerosos textos e documentos utilizam a expressão pensamento estatístico. No entanto, poucos dão uma definição formal do pensamento estatístico. Muitos parecem usar pensamento, raciocínio e literacia alternadamente em um esforço para distinguir a compreensão de conceitos estatísticos, de manipulação numérica que muitas vezes tem caracterizado uso estatístico e instrução.

De acordo com Campos, Wodewotzki e Jacobini, pensamento estatístico é:

Capacidade de relacionar dados quantitativos com situações concretas, admitindo a presença da variabilidade e da incerteza, escolher adequadamente as ferramentas estatísticas, enxergar o processo de maneira global, explorar os dados além do que os textos prescrevem e questionar espontaneamente os dados e os resultados. (CAMPOS; WODEWOTZKI; JACOBINI, 2011, p. 44).

Segundo Silva (2007), o pensamento estatístico corresponde às estratégias mentais utilizadas pelo indivíduo para tomar decisão em toda a etapa de um ciclo investigativo. Para um aluno ter a capacidade de pensar estatisticamente, ele precisa compreender no seu cotidiano muitos tipos de mensagens, principalmente as que envolvem diretamente processos de dedução estatística. 
O ensino da Estatística: competências a serem desenvolvidas

Silva $(2007$, p. 30$)$ caracteriza o chamado "ciclo investigativo" em cinco fases: "problema, plano, recolha dos dados, análise de dados e conclusões da investigação". Além disso, o pensamento estatístico é entendido como "as estratégias mentais utilizadas pelo individuo para tomar decisão em toda a etapa de um ciclo investigativo". (SILVA, 2007, p. 30).

Nesse sentido, Chance (2002) trabalha com três aspectos: como é e o que significa pensar estatisticamente, como podemos, em nossos cursos, usar e ensinar o pensamento estatístico e como avaliar, identificar se os estudantes estão pensando estatisticamente. Assim,

O pensamento estatístico ocorre quando os modelos matemáticos são associados à natureza contextual do problema em questão, ou seja, quando surge a identificação da situação analisada e se faz uma escolha adequada das ferramentas estatísticas necessárias para sua descrição e interpretação. (MALLOWS, 1998 apud CAMPOS; WODEWOTZKI; JACOBINI, 2011, p. 38).

Entender os métodos e as táticas de pensamento, que são usadas por estatísticos para resolver problemas do cotidiano, é de grande importância para despertar e aperfeiçoar o pensamento estatístico nos alunos. Dessa maneira:

Uma característica particular do pensamento estatístico é prover a habilidade de enxergar o processo de maneira global, com suas interações e seus porquês, entender suas diversas relações e o significado das variações, explorar os dados além do que os textos prescrevem e gerar questões e especulações não previstas inicialmente. (CAMPOS; WODEWOTZKI; JACOBINI, 2011, p. 39).

A grande preocupação é como desenvolver esse pensamento estatístico. Segundo Chance (2002), para atingir essa forma de pensar, acredi- 
tava-se, antigamente, que era preciso apenas a prática com trabalhos estatísticos juntamente com pessoas mais experientes em estatística. Recentemente, cresceu a preocupação em desenvolver o pensamento usando hábitos mentais e habilidades de resolução de problemas.

Chance (2002) destaca como essenciais:

- Consideração sobre como melhor obter dados significativos e pertinentes para responder à pergunta em questão;

- A constante reflexão sobre as variáveis envolvidas e curiosidade por outras formas de examinar e pensar;

- Ver o processo completo com a revisão constante de cada componente;

- O ceticismo onipresente sobre os dados obtidos;

- A relação constante dos dados para o contexto do problema e interpretação das conclusões em termos não estatísticos;

- O pensar além do livro didático e das notas do professor.

Baseados em resultados de pesquisas relacionados à Educação Estatística, Coutinho, Silva e Almouloud (2011) apontam que o progresso do pensamento estatístico acompanha algumas etapas específicas:

a) transnumeração;

b) desenvolvimento do raciocínio com modelos estatísticos; e

c) consideração da variação.

Essas etapas, em uma abordagem de resolução de problemas, de acordo com Chance (2002), podem incentivar os alunos a visualizarem o processo estatístico na sua totalidade. Talvez, a abordagem mais adequada seja desenvolver projetos com os estudantes, para que os mesmos tenham responsabilidades, formulando o plano de coleta, análise e interpretando os dados. 
O ensino da Estatística: competências a serem desenvolvidas

Silva (2007, p. 67) ressalta, ainda, que o pensamento fundamental é o "reconhecimento da necessidade dos dados, entendida como transnumeração, com o objetivo de melhorar a compreensão do problema".

Coutinho, Silva e Almouloud (2011, p. 184) acrescentam, ainda, com referências às outras etapas e no prosseguimento do pensamento estatístico, declarando que:

Quanto ao desenvolvimento do raciocínio com modelos estatísticos, ocorre, particularmente, pela análise da forma, da dispersão e das medidas estatísticas, na busca da construção de uma linguagem própria.

Finalmente, a consideração da variação é realizada pela análise da forma (como no item anterior), dispersão e medidas, isto é, usam-se os mesmos objetos para identificar propriedades distintas tais como simetria e amplitude.

Muitas vezes, a abordagem utilizada na resolução de problemas estatísticos é trabalhada de forma isolada, fazendo com que os métodos estatísticos sejam aplicados em situações limitadas. De acordo com Chance (2002), a instrução deve incentivar os alunos a visualizarem o processo estatístico na sua totalidade. Talvez, a abordagem mais adequada seja desenvolver projetos com os estudantes, para que os mesmos tenham responsabilidades, formulando o plano de coleta de dados, coletando dados, analisando os dados e, em seguida, interpretando os dados.

Simonelli e Raimundo (2011, p. 23) explicam que, em relação a necessidade do professor, que facultará o ensino da estatística, faz-se fundamental ter o conhecimento de que a fim de que a Alfabetização Estatística ocorra, é necessário prover as condições para o progresso do raciocínio estatístico. 
O ensino da Estatística: competências a serem desenvolvidas

A fim de que o desenvolvimento do raciocínio estatístico aconteça, é essencial que o professor esteja disposto, e, assim, ele deve realizar um investimento no ensino para "o desenvolvimento do raciocínio e pensamento estatístico". (SIMONELLI; RAIMUNDO, 2011, p. 23)

Oliveira Júnior et al. (2013, p. 473) discutem que o "desenvolvimento do pensamento estatístico", além de possibilitar o desenvolvimento do pensamento matemático de uma forma geral, "é fundamental à formação do cidadão reflexivo e consciente da realidade".

Dessa maneira, podemos trabalhar incentivando projetos que utilizam, atendam e desenvolvam hábitos mentais, buscando avaliar e melhorar o processo do pensamento estatístico.

Os estudantes devem acreditar nas técnicas que utilizam para tratamento dos dados. Para que exista essa crença, é necessário que eles saibam por que estão usando esta ou aquela técnica, ou ainda, como o uso de uma técnica diferente influenciaria os resultados de uma pesquisa. (CAMPOS; WODEWOTZKI; JACOBINI, 2011, p. 40).

Seguindo esse caminho, Campos, Wodewotzki e Jacobini, entendem que para desenvolver o pensamento estatístico:

É necessário que as questões de ensino e aprendizagem centralizadas nas etapas que compõem um trabalho quantitativo não configurem em um estudo isolado de métodos e de conceitos estatísticos, e que se desenvolvam num contexto significativo para o aluno, com dados reais e, principalmente, obtidos por eles mesmos. (CAMPOS; WODEWOTZKI; JACOBINI, 2011, p. 43).

Dessa forma, o professor pode encorajar os alunos, desenvolvendo o pensamento estatístico, permitindo-lhes compreender a dimensão total do problema, levando-os a questionamentos críticos a respeito dos resultados obtidos. Ainda de acordo com Campos, Wodewotzki e Jacobini 
(2011, p. 43), "ligada ao pensamento estatístico está a capacidade de espontaneamente questionar e investigar os dados e os resultados envolvidos em um contexto especifico de um problema".

Assim, Wodewotzki e Jacobini entendem que o pensamento estatístico pode ser alcançado integrando procedimentos estatísticos, pensamento analítico e planejamento. Para Wodewotzki e Jacobini (2004, apud CAMPOS; WODEWOTZKI; JACOBINI, 2011), o pensamento estatístico pode ser entendido de um lado como uma estratégia de atuação, e de outro, como um pensamento analítico, mais especificamente como um pensamento analítico crítico.

E, por meio do progresso do pensamento estatístico, faz-se possível realizar a interpretação de uma extensa e variada gama de dados, o que acaba por auxiliar no momento da tomada de decisões, essas que fazem parte do cotidiano, além de se obter sucesso em tais decisões.

Ademais, independentemente de se revelar seriamente fundamental e indispensável, o ensino de estatística não tem ganhado a atenção e a relevância necessários. Tal fato pode se dar pelo despreparo dos próprios professores, esses que as ministram na Educação Básica, ou, ainda, pela ausência de material didático que sirva como base para que esses elaborem as aulas corretamente.

Gal (2002, p. 159) salienta que o pensamento estatístico é fundamentado através de um conjunto de conceitos, e, dentre eles, os matemáticos. Não obstante, Lopes (2010, p. 93) ressalta, ainda, que o "pensamento estatístico exige um raciocínio diferente do matemático, pois a Estatística lida com incertezas". 
De acordo com Change (2002, p. 192), ao performar o pensamento de forma estatística, "o indivíduo precisa ser capaz de transpor o que lhe foi ensinado, questionando espontaneamente e investigando os resultados acerca dos dados".

Carvalho (2015, p. 06) conclui que o material de estatística que existe, atualmente, "tem se revelado insuficiente, o que leva a grande maioria dos professores a não trabalharem com este conteúdo na escola básica". Ainda, aqueles professores que trabalham com tal conteúdo, "o fazem de maneira excessivamente algorítmica, o que não favorece o desenvolvimento do pensamento estatístico por parte dos alunos".

\section{Considerações Finais}

Muitos estudos e discussões envolvendo educação estatística estão sendo desenvolvidos por diversos autores, nem todos com o mesmo ponto de vista e perspectiva sobre como se comportam a literacia, o raciocínio e o pensamento estatístico. Mas, o que podemos compreender é que todos esses conceitos estão integrados de um modo que se completam. Segundo Campos; Wodewotzki; Jacobini (2011), "Não há uma hierarquia entre essas capacidades, mas de certa forma há uma relação intrínseca entre elas". (CAMPOS; WODEWOTZKI; JACOBINI, 2011, p. 18).

Delmas (2002) propõe, por dois pontos de vista, a relação entre literacia, raciocínio e pensamento estatístico. O primeiro sustenta que cada competência tem um domínio independente das outras duas, existindo ainda sobreposição parcial entre duas ou três competências. Se esse ponto de vista está correto, podemos trabalhar com uma competência independentemente das outras, ao mesmo tempo que algumas atividades podem ser desenvolvidas em duas ou nas três competências. 
O segundo trata a literacia como uma competência que abrange as demais. Assim o raciocínio e o pensamento estatístico não têm mais domínios independentes sobre a literacia, tornando-se submetas dentro do desenvolvimento do cidadão estatisticamente letrado. Esse ponto de vista mais abrangente requer conhecimentos além da capacidade de um primeiro curso de estatística.

Ainda segundo o autor, os dois pontos de vista podem explicar a sobreposição percebida entre as três competências. Parece, no entanto, que para qualquer resultado que pode ser descrito em uma competência, existe um resultado companheiro em uma ou ambas as outras competências. Dessa maneira, Campos; Wodewotzki; Jacobini (2011) questionam em como desenvolver essas três competências.

Elas não podem ser desenvolvidas mediante instrução direta dos educadores. A ideia é a de que os professores possam atuar junto aos aprendentes de modo a favorecer a vivência dessas capacidades, possibilitando assim a construção e o desenvolvimento contínuo delas. (CAMPOS; WODEWOTZKI; JACOBINI, 2011, p. 19).

Nesse sentido, Delmas (2002, apud CAMPOS; WODEWOTZKI; JACOBINI, 2011, p. 19) ressalta que não é possivel assumir que a literacia, o raciocínio, e o pensamento estatísticos vão surgir nos estudantes se não forem tratados explicitamente como objetivos pelos professores. Em nosso cotidiano, a importância de saber lidar com dados estatísticos é crescente, mas, o que percebemos é que muitos apenas sabem, quando muito, ler tabelas e gráficos a eles apresentados. Ademais, também é preciso compreender todo o processo estatístico envolvido para que os mesmos possam ter questionamentos e clareza sobre o assunto do seu cotidiano que está sendo discutido. 


\section{Referências}

BRASIL. Ministério da Educação. Secretaria de Educação Fundamental. Parâmetros Curriculares Nacionais: Matemática $\left(1^{\circ}\right.$ e $2^{\circ}$ ciclos do Ensino Fundamental). Brasília: MEC/SEF, 2001. v. 3.

CAMPOS, C. R. A Educação estatística: uma investigação acerca dos aspectos relevantes à didática da estatística em cursos de graduação. 2007. 242 f. Tese (Doutorado em Educação) - Universidade Estadual Paulista, Rio Claro (SP), 2007.

CAMPOS, C. R. et al. Educação Estatística no Contexto da Educação Crítica. Bolema, Rio Claro (SP), v. 24, n. 39, p. 473-494, ago. 2011.

CAMPOS, C. R.; WODEWOTZKI, M. L. L.; JACOBINI, O. R. Educação Estatística: teoria e prática em ambientes de modelagem matemática. Belo Horizonte; Autêntica, 2011.

CARVALHO, A. A importância do ensino de estatística na formação inicial do professor de Matemática. 2015.

Disponivel em:

http:/ /www.ufjf.br/ebrapem2015/files/2015/10/Artigo-EBRAPEMRevisado.pdf. Acesso em: 1 ago. 2017.

CHANGE, B. L. Components of statistical thinking and implications for instruction and assessment. Journal of Statistics Education, v. 10, n.3, 2002.

Disponivel em: http://www.amstat.org/publications/jse/v10n3/chance.html. Acesso em: 2 fev. 2016.

COUTINHO, C. Q. S.; SILVA, M. J. F.; ALMOULOUD, S. A. Desenvolvimento do pensamento estatístico e sua articulação com a mobilização de Registros de Representação Semiótica. Bolema, Rio Claro, v. 24, n. 39, p. 495-514, ago. 2011. 
O ensino da Estatística: competências a serem desenvolvidas

DAMIN, W. Ensino de estatística para os anos finais do Ensino Fundamental. 2015. 97 f. Dissertação (Mestrado) - Programa de Pós-Graduação em Ensino de Ciência e Tecnologia, Universidade Tecnológica Federal do Paraná, Ponta Grossa, 2015.

Disponivel em:

http://repositorio.utfpr.edu.br/jspui/bitstream/1/1558/1/PG_PPGECT_M_Da min, Willian_2014.pdf. Acesso em: 1 jun. 2017

GAL, I. (2002). Adult statistical literacy: meanings, componentes, responsabilities. Internacional. Statistical Review, 70(1), 1-25.

Disponivel em: http://iase-web.org/documents/intstatreview/02.Gal.pdf. Acesso em: 27 jan. 2016.

GARFIELD, J. The challenge of developing statistical reasoning. Journal of Statistics Education, v. 10, n. 3, 2002.

Disponivel em: http://www.amstat.org/publications/jse/v10n3/garfield.html. Acesso em: 30 jan. 2016.

GREGÓRIO, H. M. dos S. P. O desenvolvimento da literacia estatística no 5. ${ }^{\circ}$ ano. O contributo de uma unidade de ensino. 2012. Relatório de Mestrado em Educação.

Disponivel em:

http://repositorio.ul.pt/bitstream/10451/7684/1/ulfpie042969_tm.pdf. Acesso em: 1 jul. 2017.

LOPES, C. A. E. A probabilidade e a estatística no Ensino Fundamental: uma análise curricular. Dissertação (Mestrado) - Faculdade de Educação da UNICAMP, Campinas, 1998.

O ensino da estatística e da probabilidade na educação básica e a formação dos professores. Cadernos Cedes, Campinas, v. 28, n. 74, p.57-73, abr. 2008.

Pensamento estatístico e raciocínio sobre variação: um estudo com professores de Matemática. 2003. 281 f. Tese (Doutorado em Educação) - Universidade Estadual De Campinas, Faculdade de Educação, Campinas. 2003. 
OLIVEIRA J. et al. O ensino de estatística no Ensino Médio utilizando medidas biométricas. 2013. Universidade Federal do Triângulo Mineiro. Disponivel em: http://www.jvdiesproyco.es/documentos/ACTAS/2 Comunicacion 51.pdf. Acesso em: 1 jun. 2017.

SILVA, C. B. Pensamento estatístico e raciocinio sobre variação: um estudo com professores de matemática. 2007. 354f. Tese (Doutorado em Educação) Pontificia Universidade Católica, São Paulo, 2007.

SIMONELLI, S. M.; RAYMUNDO, P. J.. Estatística aplicada à educação básica. Maringá: Cesumar, 2011. 165 p. NEAD - Núcleo de Educação a Distância. Disponivel em:

http://www.ead.cesumar.br/moodle2009/lib/ead/arquivosApostilas/756.pdf. Acesso em: 1 jul. 2017.

UNECE. United Nations Economic Commission for Europe. Making Data Meaningful Part 4: A guide to improving statistical literacy. 2012.

Disponivel em:

https://www.unece.org/fileadmin/DAM/stats/documents/writing/Making_Da ta_Meaningful_Part_4_for_Web.pdf. Acesso em: 17 fev. 2016.

WODEWOTZKI M. L. L.; JACOBINI, O. R. O Ensino de Estatística no Contexto da Educação Matemática. In: BICUDO, M. A. V. \& BORBA, M. de C. (orgs.). Educação Matemática: Pesquisa em Movimento. São Paulo: Cortez, 2004, p. 232-249. 